\title{
CORRIGENDUM
}

\section{Negative phenotypic and genetic associations between copulation duration and longevity in male seed beetles}

\author{
EA Brown, L Gay, R Vasudev, T Tregenza, PE Eady and DJ Hosken
}

Heredity (2010) 105, 576; doi:10.1038/hdy.2010.132

Correction to: Heredity (2009) 103, 340-345; doi:10.1038/ hdy.2009.80

The authors have discovered an error they would like to correct. Table 1 shows incorrect values for the coefficients of additive genetic variation $\left(\mathrm{CV}_{\mathrm{A}}\right)$. The correct values are as follows:
$\mathrm{CV}_{\mathrm{A}}$ : Longevity (total days) $=22.3$; Longevity (residual days) $=26.8$; Copulations duration (sons) $=22.5$; Copulation duration (daughters) $=19.1$.

We apologize for this error. 